\title{
Da Proteção ao Risco: Configurações da Violência Intrafamiliar na Juventude Paraense
}

\author{
Rosely Cardoso Maia ${ }^{1}$ \\ Tatiene Germando Reis Nunes \\ Lucia Isabel da Conceição Silva \\ Kátia Mesquisa da Silva \\ Universidade Federal do Pará
}

\begin{abstract}
RESUMO: Este estudo investigou a violência intrafamiliar como fator de risco no desenvolvimento dos jovens, identificando os principais agressores e os tipos de violência. Participaram 658 jovens de 13 a 24 anos, de ambos os sexos, que cursavam entre a $7^{\mathrm{a}}$ série do Ensino Fundamental e o $3^{\circ}$ ano do Ensino Médio de 10 escolas públicas de Belém. As violências verbais e físicas foram as mais identificadas. Mãe e pai apareceram como principais perpetradores da violência física, madrastas e avós da violência psicológica e da categoria outros e o padrasto da violência sexual. Os resultados apontam para compreensão da dinâmica familiar e para a proposição de políticas públicas de proteção às famílias.
\end{abstract}

Palavras-chave: adolescentes, jovens, violência na família, fatores de risco

\section{From Protection to Risk: Settings of Domestic Violence against Pará Youngsters}

\begin{abstract}
This study investigated domestic violence as a risk factor affecting the development of younsters, and aimed to identify the main perpetrators and the main types of violence. 658 youngsters of both sexes participated with ages between 12 and 24 years. They attended from 7th grade of junior high school to 3rd grade of high school in 10 different schools of Belém - Pará - Brazilian Amazon Region. Verbal abuse and physical violence were the most frequently types of violence. Parents were the main perpetrators of physical violence, stepmothers and grandmothers the main perpetrators of psychological abuse, while stepfathers and others were the main perpetrators of sexual violence. We concluded that understanding family dynamics is essential in proposing public policies to protect youngsters.
\end{abstract}

Keywords: adolescents, young adults, family violence, risk factors

Fatores como pobreza, desigualdades sociais, violência, exclusão social e vulnerabilidade, entre outros, têm levado pesquisadores a estudar a juventude correlacionando-a com esses aspectos (Abramovay, Castro, Lima, \& Martinelli, 2002). Essa tendência aparece também na preocupação de organismos internacionais como o Banco Mundial (BM), o Banco Interamericano de Desenvolvimento (BID), a Comissão Econômica para a América Latina e o Caribe (CEPAL), o Programa das Nações Unidas para o Desenvolvimento (PNUD) e a Organização das Nações Unidas para a Educação, Ciência e Cultura (UNESCO), em estudar a juventude, tendo em vista que "boa parte dos jovens da América Latina e Caribe está submetida a um risco de exclusão social sem precedentes" (Abramovay et al., 2002, p. 36).

Parece, portanto, que o risco tem sido o principal motivo que tem levado organismos públicos a investirem em pesquisas sobre os jovens, objetivando encontrar alternativas de políticas públicas que equacionem os diversos fatores que o caracterizam. Dessa maneira, a juventude tem sido a mais importante questão entre os principais problemas que desafiam as políticas de desenvolvimento social da América

1 Endereço para correspondência: Passagem Rosa Maria, n. 37, Belém, PA, Brasil. CEP: 66.070-400.E-mail: ly-maia@hotmail.com
Latina (Abramovay, 2002; Dell'Aglio, Koller, \& Yunes, 2006; Morais \& Koller, 2004).

Estudo de Poletto e Koller (2008) destaca que esses riscos estão relacionados aos acontecimentos negativos, ampliando as possibilidades de o indivíduo vir a apresentar problemas emocionais, físicos ou sociais. Em contrapartida, enfatizam a necessidade da presença dos chamados fatores de proteção, que dizem respeito às influências que podem modificar, melhorar ou alterar as respostas pessoais a determinados riscos de desadaptação (Poletto \& Koller, 2008). O surgimento de um fator de proteção pode determinar o aparecimento de outros em um dado instante e, com isso, esses fatores podem abrandar o impacto dos riscos, ampliando as opções no enfrentamento dos problemas (Amparo, Galvão, Alvez, Brasil, \& Koller, 2008).

Nos últimos anos, têm aumentado o número de pesquisas que investigam as influências da violência no desenvolvimento juvenil. Estudos têm comprovado que a violência é um potencial fator de risco ao desenvolvimento de crianças, adolescentes e jovens, favorecendo, em alguns casos, a falta de perspectivas na vida (De Antoni, Hoppe, Medeiros, \& Koller, 1999, Dell'aglio \& Siqueira, 2010; Siqueira, 2006).

Koller (2000) afirma que a violência, enquanto relevante fator de risco, é compreendida como ações e/ou omissões 
que podem interromper, dificultar, prender ou atrasar o desenvolvimento dos indivíduos. Além disso, a violência tem sido considerada como um fenômeno social, atingindo os diversos segmentos sociais (Abramovay et al., 2002). Trata-se, também, de um conceito em constante mudança, tendo em vista que vários comportamentos passaram a ser considerados, de algum modo, como atos de violência, sendo que aquilo que um determinado contexto considera violência pode não ser assim considerado em outro contexto. Por outro lado, afora essa necessária consideração contextual, existem também princípios básicos que nenhum contexto pode desconsiderar, tais como a proteção à vida, à dignidade, à segurança ou ao desenvolvimento saudável.

Por mais que a violência esteja presente em todas as esferas sociais, estudos apontam que ela tende a atingir determinados grupos, principalmente os jovens do sexo masculino, em que a vulnerabilidade social está diretamente ligada a esse índice (Abramovay, 2002). A vulnerabilidade social, segundo Prati, Couto e Koller (2009), é utilizada para "caracterizar famílias expostas a fatores de risco, sejam de natureza pessoal, social ou ambiental, que coadjuvam ou incrementam a probabilidade de seus membros virem a padecer de perturbações psicológicas" (p. 4). Esses riscos, geralmente, estão relacionados a eventos de vida negativos, que podem potencializar e predispor a efeitos de ordem social, física e/ou emocional.

Desse modo, a violência se manifesta de diversas formas, sendo a violência intrafamiliar uma das formas mais frequentes. Esse tipo de violência se configura como todo ato no qual se inclui ação ou omissão praticada por meio de membros da família ou mesmo pessoas que não possuem vínculo consanguíneo, mas que assumem função parental que venham a prejudicar "o bem-estar, a integridade física, psicológica ou a liberdade e o direito ao pleno desenvolvimento de outro membro da família" (Narvaz \& Koller, 2006, p. 08). Assim sendo, denota-se que a família, segundo uma concepção plural, pode representar um fator de risco ao desenvolvimento biopsicossocial de crianças e adolescentes.

Segundo o Ministério da Saúde (2010), a violência intrafamiliar ocorre nas relações intergeracionais e hierárquicas, atingindo mais as crianças e adolescentes, dada a sua fragilidade emocional e física. Essa violência "consiste em formas agressivas da família se relacionar, por meio do uso da violência como solução de conflito e como estratégia de educação. Inclui, ainda, a falta de cuidados básicos com seus filhos" (Brasil, 2010, p. 26-27).

A violência intrafamiliar é um fenômeno relacional e multidirecional, na medida em que compreende ações ou omissões que causem prejuízos ao desenvolvimento dos sujeitos (De Antoni, Teodoro, \& Koller, 2009). Nesse sentido, o Ministério da Saúde (2002) adverte que a violência intrafamiliar é um grave problema de saúde, estabelecendo obstáculos para o desenvolvimento econômico e social, bem como a violação dos direitos humanos.

A violência intrafamiliar, segundo Zuma (2004), concerne às diversas maneiras de relações abusivas presente entre os membros de uma família. Esse autor assegura que as vítimas são, na sua grande maioria, mulheres, crianças, adolescentes, idosos, portadores de necessidades físicas e especiais. Ele afirma ainda que os homens são os maiores agressores contra a mulher e são eles que causam os maiores danos, enquanto as mulheres são as maiores agressoras contra as crianças.

Pesquisas apontam a necessidade de um olhar mais atento à questão familiar, visto que em seus resultados a violência intrafamiliar se caracterizava como uma das possíveis "causas" da escolha pela rua. Portanto, muitas crianças, adolescentes e jovens abandonaram suas casas, em meio aos conflitos familiares, como um meio de fuga de tal realidade, sendo o abuso sexual um dos principais fatores a favorecer esse desfecho (Dutra-Thomé, Santos, \& Koller, 2010; Paludo \& Koller, 2008). Nessa perspectiva, Paludo e Koller (2008) realizaram um estudo com 17 crianças e adolescentes, na faixa etária de 11 a 16 anos, de ambos os sexos. Entre os seus resultados, as autoras apontaram os motivos que levaram os jovens a sair de casa: $12 \%$ por abuso sexual, $18 \%$ por brigas por familiares, $6 \%$ pelo uso de drogas, $29 \%$ para ajudar no sustento familiar e $18 \%$ por iniciativa própria. Com isso, os fatores de risco devem ser vistos com bastante atenção pelas pessoas que convivem com crianças, adolescentes e jovens, uma vez que tais fatores interferem de forma significativa no desenvolvimento desses sujeitos, dependendo do evento e da maneira como ele é significado pelos mesmos.

Nessa perspectiva, a definição de um fator de risco ou proteção dependerá “da qualidade das relações e da presença da afetividade e reciprocidade que estes ambientes propiciam" (Poletto \& Koller, 2008, p. 405). Assim, a necessidade de apoio da família, incluindo o cuidado às crianças, adolescentes e jovens, depende da forma como o sistema familiar está estruturado, bem como das condições nas quais ela vive. Logo, a forma como a família lida com esses sujeitos pode influenciar o seu desenvolvimento (Bronfenbrenner, 2011).

No estudo de De Antoni e Koller (2000) com meninas institucionalizadas após terem sido vítimas de maus tratos familiar, entre os resultados, as adolescentes demostraram que "apanhar é normal" e que "família que não tem briga não é família”. Segundo as autoras, as relações estabelecidas nesse contexto familiar apresentam situações de risco e podem contribuir para tornar a família e os membros familiares vulneráveis.

$\mathrm{Na}$ perspectiva pessoal, os fatores de risco que estão ligados a atitudes violentas contra crianças e adolescentes na família podem ser os transtornos de personalidade, impulsividade, agressividade, transtornos de humor, doença mental e física, deficiência física, depressão pós-parto e o uso de drogas lícitas e ilícitas. Dessa forma, crianças que ficam expostas a pais ou cuidadores agressivos têm uma forte tendência a desenvolver ao longo de suas vidas conflitos com a lei, psicopatia, fracasso acadêmico, dificuldade em se relacionar com outras pessoas e, ainda, abuso de substâncias prejudiciais à sua saúde (Cecconelo et al., 2003). Por sua vez, pais ou cuidadores que sofreram violência durante a infância ou ainda que foram criados de forma muito severa tendem a desenvolver a mesma forma de prática educativa na criação de seus filhos e ainda praticar a violência intrafamiliar (De Antoni, Teodoro, \& Koller, 2009). Entre os principais fatores de risco na família, podem-se identificar constantes níveis de tensão e falta de diálogo, histórico de uso de drogas e antecedentes criminais, bem como histórico ou relatos de 
violências, maus tratos ou abandono entre os membros da família (Brasil, 2006).

A violência intrafamiliar pode assumir diferentes formas ou expressões: violência física, violência sexual, violência psicológica e, ainda, negligência e abandono. A violência sexual está baseada em uma "relação de poder que pode incluir desde carícias, manipulação da genitália, mama ou ânus, exploração sexual, 'voyeurismo', pornografia e exibicionismo, até o ato sexual com ou sem penetração, com ou sem violência física" (Associação Brasileira Multiprofissional de Proteção à Infância e Adolescência, 1997, p. 6).

A violência psicológica ocorre em situações nas quais o sujeito é "desqualificado de suas capacidades, potencialidades, desejos e emoções ou cobrado excessivamente por pessoa significativa durante o período de crescimento e desenvolvimento" (Assis \& Avanci, 2006, p. 59). A violência psicológica pode abranger ameaça, humilhação, chantagem, ridicularização, desvalorização, entre outras (Brasil, 2006).

Além dos tipos de violência supracitados, alguns autores consideram a negligência como outra forma de violência intrafamiliar, que se refere a omissões de pais ou de responsáveis por crianças e adolescentes, caracterizada pela privação das "necessidades básicas para o desenvolvimento físico, emocional e social" desses sujeitos (Souza \& Jorge, 2006 , p. 25). Tais necessidades incluem alimentação, segurança, escola, etc. (Maia \& Williams, 2005; Siqueira, 2006). É importante destacar que o abandono é considerado como a mais grave forma de negligência (Costa et al., 2007).

Esses tipos de violência agem de maneira negativa no comportamento e no desenvolvimento de crianças e jovens. Porém, vale destacar que, na violência psicológica, os danos são resultantes de um processo lento e silencioso, envolvendo omissões e prejuízos à autoestima e, consequentemente, ao desenvolvimento e à identidade da pessoa (Day et al., 2003).

Dentre as manifestações psicológicas, pode-se perceber nestes indivíduos o sentimento de culpa, medo, agressão, e até mesmo o isolamento social e danos tardios como o aumento de transtornos psiquiátricos, dissociação afetiva, níveis intensos de ansiedade, cognição distorcida, dentre outros (Day et al., 2003). Ressalta-se também que a violência psicológica é a mais difícil de identificar, pois é um processo que causa efeitos lentos e graduais, que, pouco a pouco, deixam sentimentos de desvalorização, culpa, exploração e depressão, bem como ideação suicida.

O estudo de Rocha e Moraes (2011) com 278 crianças com idade média de 5,8 anos, 231 mães, 12 pais e 35 responsáveis de famílias cadastradas pelo Programa Médico de Família/ Niterói identificou a mãe como a principal perpetradora da violência intrafamiliar, com ênfase na violência física e psicológica. Os resultados indicaram que a mãe foi a principal agressora nos tipos de violência psicológica $(96,7 \%)$, punição corporal $(93,9 \%)$, maus tratos físicos $(49,2 \%)$ e maus tratos físicos graves $(18,3 \%)$, respectivamente.

A mãe também aparece como principal perpetradora da violência física intrafamiliar no estudo de Assis e Deslandes (2006). Esse estudo investigou 1600 adolescentes de escolas públicas do município de São Gonçalo-RJ, que listaram objetos usados pela mãe para agredi-los, causando dor ou lesões físicas. Os objetos citados foram "chinelo, sandália, tamanco, cinto, vassoura e vara de goiabeira" (p. 51), que, segundo os adolescentes, eram utilizados com a justificativa de corrigi-los e educá-los.

Os pais apareceram como os principais perpetradores da violência intrafamiliar no estudo de Franzin, Franzin e Moysés (2012). Investigaram-se 19.316 registros de notificações de violência doméstica contra crianças e adolescentes, de ambos os sexos e com idade média de 7,8 anos. Entre os casos notificados, a mãe se destaca como a principal agressora (8.896), seguida do pai (3.921). No que diz respeito à natureza dessa violência, o pai foi identificado como o principal perpetrador das violências física, sexual e psicológica, enquanto a negligência e o abandono tiveram como principal autor a figura materna.

Por outro lado, pode-se dizer que existem fatores de suma importância que funcionam como mecanismos que podem atenuar ou até mesmo prevenir a violência intrafamiliar, como participação em grupos de apoio, tratamentos psicoterápicos, relacionamentos emocionais estáveis, participação em redes de apoio sociais como trabalho, escola e igreja e ainda, a elevação da autoestima como fator de prevenção de abuso e maus tratos na família (De Antoni et al., 2009).

Na questão que envolve os resultados da interação entre risco e proteção, os estudos sobre a dinâmica familiar são de extrema importância para a compreensão do contexto familiar como uma rede de apoio ao desenvolvimento, pois poderá articular os fatores presentes aos fatores de proteção para a diminuição de um desenvolvimento de risco. Surge, assim, a necessidade de conhecer o papel da sociedade e da família na vida desses jovens, como contextos de desenvolvimento (Amparo et al., 2008; Bronfenbrenner, 2011; Hutz, Koller \& Bandeira, 1996; Sapienza \& Pedromônico, 2005; Siqueira, 2006).

Uma hipótese para ajudar nessa compreensão pode vir dos estudos sobre as novas configurações familiares, em especial, por exemplo, as famílias monoparentais femininas, nas quais cabem às mulheres, muitas vezes sozinhas, todas as responsabilidades pela educação e pelo sustento dos filhos, o que certamente, pode resultar em maiores níveis de estresse. Nessa perspectiva, o estudo de Gelinski, identifica essa vulnerabilidade de famílias monoparentais, chamando a atenção para o fato de as demandas ao serviço estratégia Saúde da Família serem mais relacionadas a questões financeiras, jurídicas ou econômicas, como Bolsa Família, trabalho ou auxílio jurídico.

Esse conjunto de dados e debates teóricos demonstra a importância de se ampliar a compreensão sobre a violência intrafamiliar, dadas as implicações sociais desse fenômeno. Assim, este estudo tem como objetivo identificar a exposição à violência contra adolescentes e jovens no contexto familiar, caracterizando os principais autores e tipos de violência.

\section{Método}

\section{Participantes}

Participaram do estudo 658 jovens, com idades entre 13 e 24 anos $(m=16,56 ; d p=2,37)$, sendo $55,6 \%$ meninas e 
$35,0 \%$ meninos $(9,4 \%$ dos participantes não registrou essa informação). Do total da amostra 23,5\% tinham entre 13 e 14 anos; $50 \%$, entre 15 e 17 anos; 20,5\%, entre18 e 20 anos; e $6,0 \%$, entre 21 e 24 anos. Tratava-se de estudantes de escolas da rede pública do município de Belém, onde 30,4\% dos jovens estavam cursando entre a sétima e oitava série do ensino fundamental e $69,6 \%$, o ensino médio.

Sobre a composição das famílias, tem-se que a mãe esteve presente em $83,5 \%$ das famílias e o pai, em apenas $61,4 \%$. Os dados indicaram ainda que 22,1\% moravam apenas com a mãe, caracterizando uma família monoparental. Entre os adolescentes participantes, 8,1\% e 3,1\% moravam com padrasto ou madrasta, respectivamente. Nas famílias, havia ainda a presença de irmão $(62,7 \%)$, avós $(77,3 \%)$ e avôs $(16,8 \%)$, sendo que $6,4 \%$ afirmaram morar com o companheiro. Em média, as famílias eram compostas por até cinco pessoas, incluindo padrastos, avós, o que reflete a mudança do perfil tradicional de família.

No momento da pesquisa, 26,3\% dos participantes estavam trabalhando, logo, conciliavam trabalho com o estudo; $37,4 \%$ afirmaram estar procurando trabalho; 4,7\% afirmaram que já precisaram parar de estudar para trabalhar. No que concerne ao turno de estudo, $41,6 \%$ frequentavam a escola pela manhã, $56,0 \%$ estudavam à tarde e somente $2,4 \%$, à noite. Ressalta-se que $48,2 \%$ dos jovens relataram ter sido reprovados na escola pelo menos uma vez.

A respeito do nível de instrução dos pais, $24,1 \%$ das mães e $5,2 \%$ dos pais tinham o ensino médio completo, respectivamente; $9,3 \%$ das mães e $26,6 \%$ dos pais tinham o ensino médio incompleto; $6,0 \%$ das mães e $10,8 \%$ dos pais tinham o ensino fundamental completo. Sobre a renda familiar, $65,0 \%$ dos jovens entrevistados declararam desconhecer essa informação. Entre aqueles que a informaram, a média foi de um salário mínimo mensal. Os pais apareceram como principais provedores do sustento em $49,0 \%$ dos casos, sendo que mães e avós representavam os principais provedores para $45,0 \%$ deles. Quando questionados sobre o recebimento de algum auxílio do governo, 66,9\% afirmaram receber o Bolsa Família e 4,6\%, auxílio do ProJovem Urbano (Silva, 2013)․․

Os dados deste estudo procedem do banco de dados da pesquisa Entre risco e Proteção: O Ser Jovem em Belém do Pará (Silva, 2013). O projeto está vinculado ao Instituto de Ciências da Educação da Universidade Federal do Pará (ICED/UFPA).

\section{Instrumento}

Foi utilizado um questionário para o levantamento dos fatores de risco e proteção, produzido pela pesquisa nacional Juventude Brasileira (Versão Fase II, Dell'aglio, Koller, Cerqueira-Santos, \& Colaço, 2011). O instrumento é composto por 77 itens de múltipla escolha, com questões que investigam aspectos referentes à caracterização

1 ProJovem Urbano objetiva promover a inclusão social de jovens brasileiros com idades entre18 a 29 anos que não concluíram o ensino fundamental, "buscando sua re-inserção na escola e no mundo do trabalho, com vistas a propiciar-lhes oportunidades de desenvolvimento humano, bem como o exercício efetivo da cidadania" (Brasil, 2008, p.14). biossociodemográfica dos participantes e variáveis relacionadas à educação, saúde, trabalho, violência, lazer e rede de apoio. Para este estudo, foi utilizada apenas a questão 31(A e D), que consiste em uma escala, na qual são apresentadas cinco situações de violência, solicitando-se aos participantes que indiquem quais já foram vivenciadas no ambiente familiar ao longo da vida e quem as infligiu com maior frequência.

\section{Procedimentos e Considerações Éticas}

O projeto de pesquisa foi aprovado pelo Comitê de Ética em Pesquisa com Seres Humanos do Instituto de Ciências da Saúde da Universidade Federal do Pará, sob protocolo $\mathrm{n}^{\mathrm{o}} 084 / 09$. A amostra foi composta de forma aleatória, por conglomerados, através do sorteio de 10 escolas públicas do município de Belém. Também foram sorteadas as turmas participantes, em cada escola. O estudo foi realizado após a concordância das instituições sorteadas. Foi solicitada a assinatura do Termo de Consentimento Livre e Esclarecido (TCLE) pelos pais (para adolescentes menores de 18 anos de idade), assim como a concordância dos próprios jovens, esclarecendo que a participação era voluntária e que as informações pessoais seriam mantidas sob sigilo. Respeitaram-se, assim, os critérios da ética na pesquisa com seres humanos, conforme a resolução $n^{0}$ 406/2012 do Conselho Nacional de Saúde (CNS). O instrumento foi aplicado coletivamente em sala de aula, por equipe treinada, com duração de aproximadamente uma hora.

\section{Resultados}

Os resultados mostraram altos percentuais de violência física e psicológica, indicando que a exposição à violência é real no contexto familiar desses jovens. Nesses tipos, cabe destacar os mesmos percentuais para a situação "soco e surra" e "ameaça e humilhação", inferindo serem essas as principais violências sofridas. Os menores percentuais aparecem para "agressão com objetos" (outro tipo de violência física) e para as situações de violência sexual ("mexeu no meu corpo contra minha vontade" e "relação sexual forçada") - ver Tabela 01.

A mãe e o pai apareceram como os principais agressores nas situações da violência física. Percebe-se que a madrasta e os avós também se apresentaram com elevados percentuais, caracterizando-se como perpetradores da violência psicológica no contexto familiar - ver Tabela 02 .

Os resultados indicam que as pessoas da convivência familiar tendem a se apresentar como principais agressores. Infere-se que a proximidade pode ser geradora de conflito e o problema ocorre quando esses conflitos geram a violência (Arpini, Quintana, \& Gonçalves, 2010), conduzindo, assim, a uma situação de fragilidade e desamparo. Portanto, tais dados sugerem um olhar mais reflexivo nesse contexto, dada a necessidade da configuração de fatores protetivos ao desenvolvimento desses jovens. 
Tabela 1. Tipos de agressão

\begin{tabular}{ccccccccc}
\hline Ameaça ou humilhação & \multicolumn{2}{c}{ Soco ou surra } & Agressão com objeto & $\begin{array}{c}\text { Mexeu no meu corpo } \\
\text { contra a minha vontade }\end{array}$ & Relação sexual forçada \\
\hline $\mathrm{N}$ & $\%$ & $\mathrm{n}$ & $\%$ & $\mathrm{~N}$ & $\%$ & $\mathrm{n}$ & $\%$ & $\mathrm{~N}$ \\
\hline 178 & $29,3 \%$ & 178 & $29,3 \%$ & 156 & $25,7 \%$ & 29 & $4,8 \%$ & 9 \\
\hline Nota. Fonte: Entre risco e Proteção: O ser Jovem em Belém do Pará (Relatório do Projeto de Pesquisa não publicado, ICED/UFPA. (SILVA, 2013).
\end{tabular}

Tabela 2. Situações de Violência Vivenciadas Dentro da Família - Indicativo de Autores que Praticaram com "Maior Frequência"

\begin{tabular}{|c|c|c|c|c|c|c|c|c|c|c|}
\hline \multirow[t]{2}{*}{ Autor (a) } & \multicolumn{2}{|c|}{ Soco ou surra } & \multicolumn{2}{|c|}{$\begin{array}{c}\text { Ameaça ou } \\
\text { humilhação }\end{array}$} & \multicolumn{2}{|c|}{ Agressão com objeto } & \multicolumn{2}{|c|}{$\begin{array}{l}\text { Mexeu no meu corpo } \\
\text { contra a vontade }\end{array}$} & \multicolumn{2}{|c|}{$\begin{array}{l}\text { Relação sexual } \\
\text { forçada }\end{array}$} \\
\hline & $\mathrm{N}$ & $\%$ & $\mathrm{~N}$ & $\%$ & $\mathrm{~N}$ & $\%$ & $\mathrm{~N}$ & $\%$ & $\mathrm{~N}$ & $\%$ \\
\hline Mãe & 92 & 51,68 & 34 & 19,10 & 100 & 64,1 & 3 & 10,34 & 0 & 0 \\
\hline Madrasta & 2 & 1,12 & 50 & 28,08 & 1 & 0,64 & 0 & 0 & 0 & 0 \\
\hline Pai & 41 & 23,03 & 7 & 3,93 & 31 & 19,87 & 1 & 3,34 & 0 & 0 \\
\hline Padrasto & 1 & 0,56 & 6 & 3,37 & 1 & 0,64 & 5 & 17,24 & 0 & 0 \\
\hline Irmão & 14 & 7,86 & 10 & 5,61 & 4 & 2,56 & 1 & 3,34 & 0 & 0 \\
\hline Avós & 8 & 4,49 & 27 & 15,16 & 6 & 3,84 & 3 & 10,34 & 0 & 0 \\
\hline Outros & 16 & 8,98 & 23 & 12,92 & 7 & 4,48 & 15 & 51,72 & 9 & 100 \\
\hline
\end{tabular}

Nota. Fonte: Entre risco e Proteção: O ser Jovem em Belém do Pará (Relatório do Projeto de Pesquisa não publicado, ICED/UFPA. (SILVA, 2013).

\section{Discussão}

Os resultados indicaram algumas consistências em relação à literatura referenciada, entre eles o que aponta a mãe como a principal perpetradora da violência intrafamiliar. Nesse sentido, surge a necessidade de um olhar mais atento à figura materna, visto que, no desenvolvimento desses jovens, a mãe tende a se caracterizar como a principal figura da rede de apoio no contexto familiar (Paludo \& Koller, 2008; De Antoni et al., 1999), especialmente nas famílias monoparentais na medida em que são responsáveis pelo funcionamento familiar (Gelinski, 2010).

Com relação aos dados que apontaram as mães como principais agressoras, alguns autores (Assis \& Deslandes, 2006; Rocha \& Moraes, 2011) afirmam que isso ocorre em decorrência de uma maior interação e convivência com os filhos. Nesse sentido, Rocha e Moraes (2011) destacam os seguintes aspectos: "a maior proximidade física com a criança, o maior tempo de permanência junto aos filhos, e a restrição à rotina doméstica, por lhes caber, culturalmente, o manejo das decisões cotidianas e a convivência doméstica" (p. 3293).

É importante destacar que, embora alguns estudos apontem a mãe como a principal autora da violência intrafamiliar, estudos indicam que ela é uma importante rede de apoio no desenvolvimento de seus filhos. Bolen e Lamb (2004) indicaram que é sobre a mãe que recai a responsabilidade de reestruturar o funcionamento e a organização da família, em situações onde crianças sofreram abuso sexual.

Dessa forma, esses resultados confirmam os dados da pesquisa na medida em que pais e mães são os principais autores da violência física, com destaque para a mãe. Neste estudo, a figura materna aparece como a principal agressora na situação "agressão com objetos". Contudo, pode-se supor a existência de uma diversidade de fatores que atuam nesta configuração, como por exemplo, um grande número de famílias chefiadas por mulheres e outras violências atuantes no macrocontexto, aspectos que, entretanto, este estudo não dispõe de dados para maior aprofundamento.

No estudo de Assis e Deslandes (2006), os próprios adolescentes atribuíram justificativas que levaram os pais ao ato de violência intrafamiliar, entre as quais o estresse no ambiente de trabalho. Os adolescentes também relataram que o não cumprimento de determinadas tarefas domésticas, por não terem limites e serem rebeldes, o próprio nervosismo dos pais e, principalmente, o mau desempenho na escola foram motivos para serem agredidos fisicamente pelos pais.

Em decorrência dessas "justificativas", alguns adolescentes consentem os atos violentos cometidos por seus pais, por considerarem-se merecedores, devido terem feito algo de errado. Ocorre ainda que os adolescentes tendem a diminuir a gravidade da situação mesmo quando relatam ter sofrido abuso físico mais severo. Essa aceitabilidade acaba reafirmando a aceitação social de que a violência seja utilizada com finalidade educativa (Assis \& Deslandes, 2006; Rocha \& Moraes, 2011).

No entanto, cabe destacar que na tentativa de "estabelecer limites através de ameaças, tapas e palmadas, os pais acabam por utilizar cada vez formas mais severas de agressão na resolução dos conflitos familiares, resultando num ciclo pernicioso e escalonando a violência intrafamiliar" (Rocha \& Moraes, 2011, p. 3292). A alta exposição da juventude à violência demonstrada nos dados aqui apresentados nos permite supor, concordando com Araújo (2002, p. 5), que, apesar das diversas conquistas no campo jurídico e político, a violência intrafamiliar continua sendo um fenômeno que se mantém "pela impunidade, pela ineficiência de políticas públicas e ineficácia das práticas de intervenção e prevenção".

A família exerce forte influência sobre a juventude e, dependendo da situação, pode agir como um potencial fator de risco ou um importante fator de proteção bem como uma 
rede de apoio social e afetiva na vida dos jovens, auxiliandoos no seu desenvolvimento físico, psicológico e social. Essa influência pode ser analisada à luz da Teoria Bioecológica de Bronfenbrenner (1996, 2011), visto que possibilita um olhar que vai além dos aspectos da pessoa em desenvolvimento, levando em consideração o contexto, o tempo e as interações que ocorrem desde o contex to imediato, compreendido como microssistema, ao mais distante, denominado macrossistema. Essas estruturas (micro-, meso-, exo- e macrossistema) estão organizadas em formas de encaixe, uma interligada à outra, influenciando-se mutuamente (Bronfenbrenner, 1996, 2011).

Desse modo, diversos fatores podem ajudar a explicar ou estão relacionados à violência sofrida pelos jovens, variando desde as condições socioeconômicas dos pais, a cultura em que vivem, até a baixa escolaridade. A violência pode ser, assim, caracterizada como multifatorial e deve ser compreendida bioecologicamente como resultante da interação de fatores sociais, familiares e pessoais (Cecconelo et al., 2003; Garbarino \& Eckenrode, 1997; Pelcovitz et al., 2000; Septimus-Berger, 1999).

Portanto, a família enquanto potencial fator de proteção e rede de apoio precisa ser a instituição na qual garantirá o pleno desenvolvimento de crianças, adolescentes e jovens. Ademais, é necessário compreender a violência intrafamiliar como um fenômeno complexo, tendo em vista que em termos de delineamento de pesquisa, torna-se importante que seja levada em consideração a influência que uma relação exerce sobre as demais relações em um determinado contexto. (Bronfenbrenner, 2011). Nesse caso, tornam-se urgentes políticas de proteção para as famílias de forma a prevenir a violência e mais do que isso, fortalecer o papel protetivo desse contexto para o desenvolvimento saudável de crianças, adolescentes e jovens.

\section{Considerações Finais}

Discutir a juventude e a sua relação com a violência tem sido algo recorrente na atual conjuntura diante dos dados que já foram apresentadas no início deste trabalho. Tais dados são preocupantes, pois refletem a maneira como a juventude tem se inserido, ou mesmo deixado de se inserir, nos diferentes contextos sociais. No entanto, é necessário ter um olhar crítico acerca dos problemas e desafios que os jovens vêm enfrentando, pois há uma constante e intensa transformação que, de maneira direta, atinge as suas vidas. Essas transformações dizem respeito às relações familiares, à inserção no mundo trabalho, à escolarização e à formação, entre tantas outras.

Este estudo identificou alta exposição dos jovens paraenses à violência intrafamiliar, o que parece configurar a família como potencial fator de risco ao seu desenvolvimento, invertendo-se, assim, o seu papel de protetora. Tratase, portanto, de um dado relevante e que merece ser problematizado, já que põe em cheque um contexto classicamente protetivo e de socialização dos sujeitos (Silva, 2013).
Cabe questionar, quais fatores ou situações acabam por influenciar essa possível mudança ou inversão de papel? $\mathrm{O}$ que esses dados podem dizer sobre as atuais condições ou posições das mulheres nas famílias? Pensa-se que essas questões precisam ser aprofundadas em estudos posteriores e discutidas à luz de outros estudos que apontam para a família como um dos principais pontos da rede de apoio dos adolescentes e jovens.

Pensa-se que estes resultados podem contribuir para fomentar políticas públicas voltadas para esse público, visando prestar apoio físico, social e psicológico às vítimas dessa violência. Essas iniciativas devem buscar, ainda, coibir e conscientizar a população sobre os danos causados pelos abusos sofridos no contexto familiar, possibilitando que os fatores de proteção da família sejam maximizados, elevandose consequentemente a sua função de apoio.

As limitações deste estudo corresponderam tanto à ausência de análises diferenciadas por sexo quanto ao desenho quantitativo para o entendimento da dinâmica risco e proteção frente à violência. Demonstra-se, assim, a necessidade de novas pesquisas no contexto de violência intrafamiliar, investigando as diversas correlações de fatores e ainda, estudos referentes à percepção dos jovens que sofreram violência intrafamiliar sobre a sua rede de apoio.

\section{Referências}

Abramovay, M. (2002). Juventude, violência e vulnerabilidade social na América Latina: Desafios para politicas públicas. Brasília: UNESCO, BID.

Associação Brasileira Multiprofissional de Proteção à Infância e Adolescência (1997). Abuso sexual contra crianças e adolescentes: Proteção e prevenção-guia de orientação para educadores. Petrópolis, RJ: Autores \& Agentes \& Associados.

Amparo, D., Galvão, A., Alvez, P., Brasil, K., \& Koller, S. (2008). Adolescentes e jovens em situação de risco psicossocial: Redes de apoio social e fatores de proteção. Estudos de Psicologia, Natal, 13(2), 165-174.

Araújo, M. (2002). Violência e abuso sexual na família. Psicologia em Estudo, Maringá, 7(2), 3-11.

Arpini, D., Quintana, M., \& Gonçalves, C. (2010). Relações familiares e violência em adolescentes em situação de rua. Psicologia Argumento, 28(63), 325-336.

Assis, S., \& Deslandes, S. (2006). Abuso físico em diferentes contextos de socialização infanto-juvenil. In C. A. Lima (Ed.), Violência faz mal à saúde (pp. 47-57). Brasília: Ministério da Saúde.

Assis, S., \& Avanci, J. (2006). Abuso psicológico e desenvolvimento infantil. In C. Lima (Ed.). Violência faz mal à saúde (pp. 5967). Brasília: Ministério da Saúde.

Bolen, R. M., \& Lamb, J. L. (2004). Ambivalence of nonoffending guardians after child sexual abuse disclosure. Journal of Interppersonal Violence, 19, 185-211.

Ministério da Saúde. (2002). Violência Intrafamiliar: Orientações para a prática em serviço. Cadernos da Atenção Básica, 8, 07-88. 
Ministério da Saúde. (2006). Violência faz mal à saúde (1 $1^{\mathrm{a}}$ edição Série B. Textos Básicos de Saúde). Brasília, DF: Ministério da Saúde.

Brasil. (2008). Projeto Pedagógico Integrado - PPI: ProJovem Urbano. Brasília, DF: Secretaria Nacional de Juventude.

Brasil. (2010). Linha de cuidado para a atenção integral à saúde de crianças, adolescentes e suas famílias em situação de violências: orientação para gestores e profissionais de saúde. Brasília: Ministério da Saúde. Secretaria de Atenção à Saúde. Departamento de Ações Programáticas Estratégicas.

Bronfenbrenner, U. (1996). A ecologia do desenvolvimento humano: Experimentos naturais e planejados (M. A. V. Veronese, Trad). Porto Alegre: Artes Médicas. (Trabalho original publicado em 1979)

Bronfenbrenner, U. (2011). Bioecologia do desenvolvimento humano: Tornando os seres humanos mais humanos (A. C. Barreto, Trad). Porto Alegre: Artes Médicas.

Cecconelo, A., De Antoni, C., \& Koller, S. (2003). Práticas educativas, estilos parentais e abuso físico no contexto familiar. Psicologia em Estudo, 8(Número Especial), 45-54.

Chauí, M. (1985). Participando do debate sobre mulher e violência. Perspectivas Antropológicas da Mulher. Rio de Janeiro: Zahar, 25-62.

Costa, M., Carvalho, R., Bárbara, J., Santos, C., Gomes, W., \& Sousa, H. (2007). O perfil da violência contra crianças e adolescentes, segundo registros de Conselhos Tutelares: Vítimas, agressores e manifestações de violência. Ciência \& Saúde Coletiva, 12(5), 1129-1141.

Day, V., Telles, L., Zoratto, P., Azambuja, M., Machado, D., Silveira, Debiaggi, M., Reis, M. G., Cardoso, R. G., \& Blank, P. (2003). Violência doméstica e suas diferentes manifestações. Revista de psiquiatria, 25(1), 9-21.

De Antoni, C., Hoppe, M. W., Medeiros, F., \& Koller, S. (1999). Uma família em situação de risco: Resiliência e vulnerabilidade. Interfaces: Revista de Psicologia, 2(1), 81-85.

De Antoni, C. \& Koller, S. H. (2000). A visão de família entre adolescentes que sofreram violência intrafamiliar. Estudos de Psicologia, 5(2), 347- 382.

De Antoni, C., Teodoro, M., \& Koller, S. (2009). Coesão e hierarquia em famílias fisicamente abusivas. Universitas Psychologica, 8(2), 399-411.

Dell'aglio, D., \& Siqueira, A. (2010). Preditores de satisfação de vida de jovens em situação de vulnerabilidade no Sul do Brasil. Psicodebate, 10, 213-230.

Dell'aglio, D., Koller, S., Cerqueira-Santos, E., \& Colaço, V. (2011). Revisando o questionário da juventude brasileira: Uma nova proposta. In D. D. Dell'Aglio \& S. H. Koller (Orgs.), Adolescência e Juventude: Vulnerabilidade e contextos de proteção (pp. 259-270). São Paulo: Casa do Psicólogo.

Dutra-Thomé, L., Santos, E., \& Koller, S. (2011). Exploração sexual e trabalho na adolescência: Um estudo de caso. Universitas Psychologica, 10(3), 881-896.

Franzin, L. C. S., Franzin, F. M., \& Moysés, S. T. (2012). Violência doméstica contra crianças e adolescentes: prevalência em cidade do Sul do Brasil. Colloquium Vitae, 4(2), 79-84.

Garbarino, J., \& Eckenrode, J. (1997) Understanding abusive families. New York: Jossey-Bass.
Gelinski, C. (2010). Proteção social em saúde para famílias vulneráveis com monoparentalidade feminina via estratégia saúde da família (Tese de doutorado não publicada). Programa de Pós-Graduação em Sociologia Política da Universidade Federal de Santa Catarina, Brasil.

Hutz, C., Koller, S., \& Bandeira, D. (1996). Resiliência e vulnerabilidade em crianças em situação de risco. Coletâneas da ANPEPP, 1(12), 79-86.

Koller, S. (2000). Violência doméstica: Uma visão ecológica. In Amencar (Ed.), Violência Doméstica (pp. 32-42). Brasília: UNICEF.

Maia, J., \& Williams, L. (2005). Fatores de risco e fatores de proteção ao desenvolvimento infantil: Uma revisão da área. Temas em Psicologia, 13(2), 91-103.

Morais, N., \& Koller, S. (2004). Abordagem ecológica do desenvolvimento humano, psicologia positiva e resiliência: a ênfase na saúde. In S. H. Koller (Ed.), Ecologia do desenvolvimento humano: Pesquisa e intervenção no Brasil (pp.91-107). São Paulo: Casa do Psicólogo.

Narvaz, M., \& Koller, S. (2006). Famílias e patriarcado: Da prescrição normativa à subversão criativa. Psicologia \& Sociedade, 18(1), 49-55.

Nunes, T. G., Pontes, F. A. R., Silva, L. I. C., \& Dell'Aglio, D. D. (2014). Fatores de risco e proteção na escola: Reprovação e expectativas de futuro de jovens paraenses. Revista Quadrimestral da Associação Brasileira de Psicologia Escolar e Educacional, 18(2), 203-210.

Paludo, S., \& Koller, S. (2008). Toda criança tem família: Criança em situação de rua também. Psicologia \& Sociedade, 20(1), 42-52.

Pelcovitz, D., Kaplan, S., Ellenberg, A., Labruna, V., Salzinger, S., Mandel, F., \& Weinner, M. (2000). Adolescent physical abuse: Age at time of abuse and adolescent perception of family functioning. Journal of Family Violence, 15(4), 375-389.

Poletto, M., \& Koller, S. (2008). Contextos ecológicos: Promotores de resiliência, fatores de risco e de proteção. Estudos de Psicologia-Campinas, 25(3), 405-416.

Prati, L., Couto, M., \& Koller, S. (2009). Famílias em vulnerabilidade social: Rastreamento de termos utilizados por terapeutas de família. Psicologia: Teoria e Pesquisa, 25(3), 403-408.

Rocha, C., \& Moraes, P. (2011). Violência familiar contra a criança e perspectivas de intervenção do Programa Saúde da Família: A experiência do PMF/Niterói (RJ, Brasil). Ciência e Saúde Coletiva, 16(7), 3285-3296.

Ruzany, M., \& Meirelles, Z. (2009). Adolescência, juventude e violência: Identificação, abordagem e conduta. Adolescência \& Saúde, 6(3), 52-60.

Sapienza, G., \& Pedromônico, M. (2005). Risco, proteção e resiliência no desenvolvimento da criança e do adolescente. Psicologia em Estudo - Maringá, 10(2), 209-216.

Septimus-Berger, A. (1999). Adolescent physical abuse: Predictive factors. The Sciences and Engineering, 59, 3713-3735.

Silva, L. (2013). Entre risco e proteção: O ser jovem em Belém do Pará (Relatório final de pesquisa não publicado). Belém: ICED/FAED. 
Siqueira, A. (2006). Instituições de abrigo, família e rede de apoio social e afetivo em transição ecológica na adolescência. (Dissertação de mestrado não publicada). Universidade Federal do Rio Grande do Sul, Brasil. Retirado de http:/www.lume. ufrgs.br/bitstream/handle/10183/5955/000522590.pdf?...1

Souza, E., \& Jorge, M. (2006). Impacto da violência na infância e adolescência brasileiras: Magnitude da morbimortalidade. In C. A. Lima (Ed.), Violência faz mal à saúde (pp. 23-38). Brasília: Ministério da Saúde.
Zuma, C. E. (2004). A Violência no Âmbito das Famílias: identificando práticas sociais de prevenção. (Trabalho de Conclusão de Curso de Especialização não publicado). Rio de Janeiro: Universidade do Federal do Rio de Janeiro. Retirado de http://www.noos.org.br/acervo/A-violencia-no-ambitodas-familias-identificando-praticas-sociais-de-prevencao.pdf 